larva and egg, and notes on the distribution, habits and vector status in relation to human and (where known) animal disease.

The last 100 pages of this work are devoted to general discussions and concise reviews of the biology of the Malayan anophelines that, in fact, cover far more ground than is implied by the title. There is an excellent section on speciation in which the author airs his well-informed views on the very moot question of what constitutes a subspecies and how one should refer to allopatric or sympatric variants, these being all too common among the Culicidae. $\mathrm{He}$ points to the urgent need for further hybridization and cytogenetic studies in certain species, particularly the barbirostris and leucosphyrus groups, along the lines that have yielded such valuable data on the Anopheles gambiae group of the African continent in the hands of Davidson, Coluzzi and others.

The final sections on circadian rhythms in mosquitoes, biting habits and host preferences and, finally, the important parts played by certain species in the trans. mission of malaria, filariasis and arbor virus diseases, provide a concise reference source to data that have been neatly compiled from a wide variety of sources. Not the least accomplishment of the author and publisher is the publication of such a valuable monograph, with so many first class illustrations, at so modest a price. Although this type of work, naturally enough, tends to gravitate largely to the bookshelves of the specialist, there is much material of a far broader interest here to those concerned with general systematics, mosquito behaviour and vectorborne diseases. I can fully endorse the opinion of the director of the Institute for Medical Research, Malaysia, who, in his foreword, concluded, "I have no doubt [this monograph] will be for many years the reference book for the Anopheline fauna of S.E. Asia".

W. Peters

\section{PHOTOSYNTHESIS AND LIFE}

\section{Photosynthesis}

By G. E. Fogg. (Modern Biology.) Pp. xii + 116+12 plates. (English Universities Press: London, September 1968.) $21 s$ paper; $35 s$ boards.

THIs moderately priced and attractively produced little book is an attempt by an eminent botanist to provide for those beginning the study of photosynthesis a simple introduction to the important recent discoveries about the subject, and to place them in perspective in relation to the role of photosynthesis in the whole plant and to its importance in world cconomy. I found the book most enjoyable and can thoroughly recommend it to those students with a sound background of the basic physical sciences. This implied reservation is not a criticism of the book but an acceptance of the difficulties which, as a biochemist, I feel beset university biology teachers at this moment. First year students without A-level chemistry and some post $\mathrm{O}$-level knowledge of physics and mathematics will find even this lucid text difficult. For example, will they understand the simple equation for Beer's law (page 25) or the concept of redox potential or that of energy levels in an excited molecule? Furthermore, even those with satisfactory A-level combinations and grades, unless they are studying chemistry and/or biochemistry alongside their photosynthesis course, may not fully appreciate the significance of the Calvin cycle, and terms like NADPH and ferredoxin may be littlo more than words.

Professor Fogg's book can make a real contribution to the teaching of photosynthesis to students who have some of the deficiencies indicated, if it is used in conjunction with background tutorials at appropriate stages of the discussion or if the students are attending a biochemistry course at the same time.

It is my feeling, as a non-expert, that the wider issues which Professor Fogg raises in his last chapter ("Photosynthesis and Life: Past, Present and Future") will also become more meaningful if the major portion of his book is fully appreciated. A minor criticism is that $\sim P$ is used to denote linkages both with a low $\Delta F$ of hydrolysis and with a high $\Delta F^{\prime}$ of hydrolysis. This might cause a little confusion, because it is normal biochemical practice to confine the use of $\sim P$ to the latter group of compounds.

T. W. GooDWIN

\section{IMIDOYL HALIDES}

The Chemistry of Imidoyl Halides

By Henri Ulrich. Pp. $x+238$. (Plenum Press: New York, 1968.) $\$ 12.50$.

THIs book constitutes a clearly written comprehensive review of the synthesis and properties of imidoyl halides which are defined as reactive organic compounds containing a halogen atom attached to the carbon atom of a carbon-nitrogen double bond. Individual chapters are centred around the following types of compound:

$\mathrm{X}(\mathrm{Y}) \mathrm{C}=\mathrm{NR}, \mathrm{X}(\mathrm{R}) \mathrm{C}=\mathrm{NOH}, \mathrm{X}(\mathrm{R}) \mathrm{C}=\mathrm{NNR}_{2}$, and

(X) $\mathrm{C}^{\left\lceil\left(\mathrm{CH}_{2}\right)\right\rceil} \underset{\mathrm{N}}{\mathrm{N}}$ where $\mathrm{X}=$ halo; $\mathrm{R}=$ alkyl or aryl;

and $\mathrm{Y}=$ halo, $\mathrm{R}, \mathrm{NR}_{2} \mathrm{OR}$, or SR.

A number of other compounds, for example, those with substituents such as CN, NCO, OCN, NCS, SCN and $\mathrm{CO}_{2} \mathrm{H}$ attached to the $-\mathrm{C}(\mathrm{X})=\mathrm{N}-$ system and the aromatic compounds, halopyridines, halopyrimidines and halo-1,3,5-triazines, are discussed briefly. In general, each chapter is divided into four sections: (i) an introduction consisting of a brief history of the class of compound, nomenclature, stability, summaries of methods of synthesis and types of reactions undergone and possible uses in synthesis; (ii) methods of synthesis including specific examples with experimental details and tables of individual compounds of the class which have been characterized by either melting points or boiling points; (iii) physicochemical properties including tables of I.R. data; and (iv) chemical behaviour classified according to the type of reaction undergone including reactions with $\mathrm{O}-\mathrm{H}, \mathrm{S}-\mathrm{H}$, $\mathrm{N}-\mathrm{H}$ and $\mathrm{C}-\mathrm{H}$ bonds and addition and elimination reactions. Each chapter is well supported by literature references and the book has author and subject indexes. An appendix with forty-eight references reviews the literature on imidoyl halides which appeared in the last half of 1967 and the first two months of 1968.

Organic and biological chemists will find this book very useful for the synthesis of many nitrogen-containing compounds. The inclusion of experimental details of the general procedures for the synthesis of the various types of imidoyl halides makes this a valuable laboratory manual, especially as in many cases the original literature references are not readily available.

\section{K. BROCKLEHURST}

\section{HETEROCYCLIC CHEMISTRY}

\section{Principles of Modern Heterocyclic Chemistry}

By Leo A. Paquette. (The Organic Chemistry Monograph Series.) Pp. xiv +401 . (Benjamin: New York and Amsterdam, 1968.) n.p.

ONE of the chief difficulties in teaching heterocyclic chemistry is to decide whether to interleave it with carbocyclic material even at the elementary stage, or whether to provide a course only after the basic situations and processes of organic chemistry have been encountered: both approaches have their advantages, but neither is without its problems. This volume is clearly designed to 